\title{
A perspective on continuing medical education
}

\author{
John Cox
}

Although the title 'continuing professional development' is likely to supersede 'continuing medical education', my bias is towards the latter more familiar term. CME has always been an integral component of a consultant's responsibilities. In the Edinburgh Declaration (1988) teaching of medical students must include preparation for "lifelong active learning"; knowledge of the scientific basis of psychiatry and familiarity with selected literature are embedded within our postgraduate training tradition and the statutes of the College.

Yet the pace of recent advances is such that to keep fully abreast of developments in, for example, neuro-imaging, cognitive and behavioural therapy, the Children Act or post headinjury neuropsychiatric sequelae, is daunting and can only be maintained by access to appropriate educational events and guided study. reinforced by continuous peer pressure.

A working group of the College's Education Committee (1991) on CME recommended the establishment of a special committee to set standards of CME, to determine the rate and style of its introduction, to decide what sanctions, if any. there should be for non-compliance and to consider how this College activity should be funded.

The recently established CME Department is the first step towards implementing these recommendations. Spurred on by an apparent anti-medical streak within the NHS reforms and increased knowledge of health issues by patients, this surge towards formalising CME is seemingly inexorable. Other considerations include the need for more formalised and structured postgraduate training and the recognition that this should optimally be carried out by trained trainers. Furthermore, once the principle of accreditation in the Calman proposals has been accepted and the criteria for the award of the Certificate of Completion of Specialist Training agreed then it is only a stone's throw from the need to determine the criteria for re-accreditation.

Were the College not to take an initiative in CME with appropriate alacrity then this could be imposed by a purchaser or mandated by an NHS Executive. Any such educational requirement imposed from outside the profession is unlikely to be effective or to be fully implemented - as we know from responses to recent hasty government edicts.

\section{National Conference on CME October 1993}

CME was regarded as of sufficient national importance to be the subject of an editorial in The Independent prior to a meeting on accreditation held at the Royal College of General Practitioners. Although this conference was concerned primarily with re-accrediting general practitioners and their CME, there was much in the content of the talks which was immediately relevant to psychiatrists.

We were informed that re-accreditation was compulsory in certain States in North America but was voluntary in Holland, Australia and Canada. There was talk of the Royal College of Obstetricians and Gynaecologists proposing to withdraw Fellowship of their College from a consultant who failed to meet their standards for accreditation.

A distinction was made between the new General Medical Council procedures for identifying and correcting poor performance from the underlying principles of $\mathrm{CME}$ - although these two aspects of public scrutiny are to an extent linked.

The contribution from the Assistant Registrar of the United Kingdom Central Council for Nursing Midwifery and Health Visitors described the process for post-registration of nurses who must complete a 'Personal, Professional Profile'. This has particular appeal and is, I believe, relevant to the CME debate within the College.

\section{How should we move forward?}

There is a need to think critically and clearly about all aspects of $\mathrm{CME}$ before committing consultants to this additional demand on their time.

(a) What will be the criteria for accreditation and for re-accreditation? 


\section{EDITORIAL}

(b) Is CME to be voluntary, expected or mandatory? I am in favour of a gradualist approach because if it is imposed on psychiatrists from widely diverse specialities it is unlikely to be fully effective and will not therefore meet the expectations of improved service. We would not wish to see consultants take part in CME more to obtain credit points than to genuinely enhance their professional development.

(c) What action, if any, is the College to impose on doctors who do not meet the criteria?

(d) Is there a risk that the College could be brought into disrepute through accredited consultant psychiatrists carrying out a poor standard of clinical practice resulting in complaint or litigation?

I am not sure that too centralised a scheme whereby completed CME data are only held in the College is necessarily best. It might be wise to ensure that there is a regional CME tutor with a delegated responsibility of encouragement, exhortation and monitoring of training and its uptake. But the College would determine national standards. Accreditation could be mandatory at least for educational supervisors, course organisers, examiners, regional advisers and merit award holders. A regional tutor could meet con- sultants and other career grade psychiatrists annually to develop their Personal Professional Profiles. It is my experience that such formalised peer pressure is the best safeguard for the public with regard to ensuring we keep up-to-date and competent to practice.

Purchasers and providers will also have their own contractual reasons for consultants meeting local needs based upon highest possible standards. The eventual time requirements under the College proposals are considerable and need to be carefully costed.

If CME is appropriately resourced and there is protected time then these developments are to be welcomed; the public being informed that financial and other resources will be necessary if the process is to improve clinical services. Otherwise CME may remain the College's pipe dream or management's nightmare.

\section{References}

ASSOCIATION FOR MEdical EDUCATION IN EUROPE (1988) Edinburgh Declaration. (Edinburgh Conference, 1988) Dundee: AMEE.

ROYAl COLLEGE OF PSYCHIATRISTS (1991) Report of the Working Group On CME.

Professor John Cox, Dean, Royal College of Psychiatrists 